\title{
Living Arrangement of Older People: A Study of Community Living Elderly from Nepal
}

\author{
Satya Narayan Singh1, Amrita Upadhyay ${ }^{2}$, Hom Nath Chalise ${ }^{3,4^{*}}$ (1) \\ ${ }^{1}$ Torrens University, Sydney, Australia \\ ${ }^{2}$ Ask Foundation/Danphe Care, Dillibazaar, Kathmandu, Nepal \\ ${ }^{3}$ Mphil Lead PhD Program, Central Department of Population Studies, Tribhuvan University, Kathmandu, Nepal \\ ${ }^{4}$ Population Association of Nepal, Kathmandu, Nepal \\ Email: *chalisehkpp@gmail.com
}

How to cite this paper: Singh, S.N., Upadhyay, A. and Chalise, H.N. (2021) Living Arrangement of Older People: A Study of Community Living Elderly from Nepal. Advances in Aging Research, 10, 133-142. https://doi.org/10.4236/aar.2021.106008

Received: October 1, 2021

Accepted: November 23, 2021

Published: November 26, 2021

Copyright $\odot 2021$ by author(s) and Scientific Research Publishing Inc. This work is licensed under the Creative Commons Attribution International License (CC BY 4.0).

http://creativecommons.org/licenses/by/4.0/ (c) (i) Open Access

\begin{abstract}
Background: Aging has caused changes in the structure of families that raises reflections on the sustainability of the traditional models of family care for older adults. The aim of this article is to analyze the situation of living arrangements of Nepalese older people. Methods: This study is a secondary analysis of structured interview data collected by the Central Department of Population Studies at Tribhuvan University (TU) via a cross-sectional survey of community-dwelling persons aged $60+$ in the Pharping area of Kathmandu. For this study, there were 1326 valid responses. Results: Findings show over four-fifths of respondents $(81.3 \%)$ were living with family members, far more than with a spouse only (11.6\%), alone $(6.2 \%)$, and others $(0.9 \%)$. The proportion of Populace residing alone tends to increase with the increase in age of respondents; more widowers tend to live alone compared to those in marital unions; more elderly males without living children tend to live alone compared to those who have at least one living child. The sex of the respondents, marital status, ethnicity, income situation, and feeling of insecurity have significant differences in the living arrangement of older people in this study. Conclusion: Traditionally, Nepalese older adults are contented to live with their family members. The government of Nepal should promote the traditional living arrangements of older people through some incentives providing for family members taking care of their senior citizens.
\end{abstract}

\section{Keywords}

Living Arrangements, Older People of Nepal, Care of Older People, Social Security 


\section{Introduction}

Population ageing is occurring around the globe at different rates. Every country in the world is expected to experience a substantial increase in the proportion of the population aged 60 years or over regardless of a nation's level of development [1]. Aging is the result of both longer life expectancy and declining fertility rates [2]. Factors that contributed to people living longer are advances in education, a revolution in technology, development in medicine, food distribution, and public health [3]. On the other hand, increasing age results in decline in health and functional status, physical and cognitive capacities, but the number of chronic diseases and disability increases [4].

The living arrangement becomes an important constituent of the overall well-being of the elderly in developing countries. It is known that the type of living arrangement can interfere in social interactions of the older adults and in the provision of available resources in their daily lives. It provides some indication of the level of actual support available to them. Western industrialized and developed countries have developed social security, pension, and public health systems to support older adults and supplement their personal and family resources. In contrast, in many developing countries, little or no such government-funded institutional support is available [5]. Older adults in developing countries often require social, economic, and physical assistance, but many are ill equipped to provide for themselves because of poor health and a lack of private savings. Consequently, they tend to rely heavily on members of their household and family for their well-being and survival [6]. Households throughout the developing world represent the main institution responsible for the distribution of goods and services between generations, and they are the principal venue through which age and kinship roles are expressed [7].

\section{Context of Nepal}

Individuals 60 years and older are considered older people in Nepal. In recent decades, the life expectancy of the Nepalese are increasing rapidly [8] and the elderly population growth rate is higher than the total population growth rate [1]. Living arrangements for the elderly was not an issue a few decades ago in most developing countries, including Nepal, because the elderly were expected to be cared for by the family [6]. However, issues concerning household structure, care and support for older persons in developing countries are becoming increasingly important as the proportion of older persons are increasing [6]. Studies shows more than $80 \%$ of the elderly live with their children and taking care of the elderly is considered the responsibility of family members [2] [9]. In Nepal, the family, as a social institution, is the main source of support and care for its older members, helping them with day-to-day activities and giving them all kinds of support. Traditional family values, including revering elders, and providing care and support to the elderly is considered a social norm and a moral duty for family members. Anecdotal evidence suggests that most primary caregiving is provided 
by either wife or daughter-in-law. Daughter's once they get married they move to the husband's home and taking care of the husband's family is considered their major duty and responsibility. As there is no formal care system of the elderly developed [10] still parents directly or indirectly think children as insurance for old age. Culturally taking care of older parents is considered a responsibility of children mainly sons [11]. But, recently with the nucleation of family and permanent migration of son's family to foreign countries daughter's taking care of their parents are also increasing.

With increasing urbanization and the effect of modernization, the size of households is decreasing in Nepal [2] [9]. In traditional rural societies families are often more extended than in modern urbanized societies where the independent nuclear family is predominant. In the process, extended kinship ties weaken and the nuclear family becomes an independent unit. This weakening of ties with family members reduces social interaction and financial and physical support for the older generation [12]. Separate living arrangements are required for them as countries develop. Therefore in this context, the living arrangement issues of the elderly need attention because their welfare depends on it. Given this backdrop of rapid demographic and family changes, it is important to explore the current nature of living arrangements. The purpose of this paper is to present the situation of living arrangement of Nepalese older people.

\section{Methodology}

This research is a secondary analysis of cross-sectional data from a survey conducted by Tribhuvan University's (TU) Central Department of Population Studies (CDPS) in six Village Development Committees (VDCs) of the Pharping area in Kathmandu, Nepal [13]. The VDCs in this study were a convenience sample, as they comprise the catchment area of one community hospital in Pharping. Each VDC has nine wards (the lowest-level political unit). Individual 60 years and older were the respondents for this study. Details of the methodology is published somewhere [13] [14]. Total sample size for this study was 1355. For the purpose of this study, people who reported clinical diagnosis of Alzheimer's disease or another dementia were excluded, as were those for whom some demographic data were missing; there were 29 such cases. Thus the total sample size for this analysis was 1326 older adults.

During the survey, a question was asked to respondents about their living arrangements, i.e. to whom the elderly was residing. Finally, it was categorized as living alone, with a spouse, and with family members. There were a few cases living in the institution or with unfamiliar people as well. That was not included in the final analysis.

SPSS version 20 was used to analyze the data. Chi-square assessed demographic differences for selected variables Age, Sex, Marital status, self-reported health, and feeling of insecurity, using $\mathrm{p}<0.01$ to indicate a significant difference. This study was approved by the Nepal Health Research Council (Ref No. 211, Reg No. $66 / 2012$ ) as conforming to ethical research standards. 


\section{Results}

Table 1 shows the living arrangement of older people. Out of 1326 older people, highest proportion were living with son/daughter-in-law (66.3\%), followed by $11.6 \%$ living with spouse, $6.2 \%$ were living alone, $6.1 \%$ with daughter/son-in-law, $4 \%$ unmarried son/daughter, $2.3 \%$ with grandchildren, $1.4 \%$ brother/sister-in-law, $1.3 \%$ with other family members and $0.9 \%$ other. As living with son/daughter-in-law, daughter/son-in-law, grandchildren, brother/sister-in-law is also living with a family member. So, the living arrangement is further categorized into four categories: living alone, Spouse, family members, and others as shown in Table 2. The majority of older persons were living with family members ( $81.3 \%)$, followed by a spouse (11.6\%), alone (6.2\%), and others (0.9). As the total cases in others were only 12 , they are omitted for the final analysis considering only three categories of living arrangement: Family member, spouse, and alone. This study further found major causes of living alone were having no own children, children living far from parents, no support from children, the marriage of a daughter, death of a spouse, and personal desire also.

Differentials of living arrangements are shown in Table 3. Sex, Marital status, Ethnicity, self-reported health, income situation, age, and feeling of insecurity was used as "differential variables". The proportion of residing alone tends to increase with the increase in age of respondents; more widower tends to live alone compared to those in marital unions; more elderly males without living children tend to live alone compared to those who have at least one living child. Among the caste/ethnic groups, a relatively higher proportion of Brahmin elderly (11.0\%) compared to other caste/ethnic groups were residing alone. Further, older people having income situation less adequate has higher proportion living alone (11.1\%) compared to just adequate and more than adequate. With marital status, the proportions of living alone are high among those who are in the state of widowhood (10\%), separated/divorced (33\%), and never married (37.5\%) (not shown in detail here).

Table 1. Detail living arrangement of older persons, community, Nepal.

\begin{tabular}{ccc}
\hline Living Arrangement & Number & Percentage \\
\hline Alone & 82 & 6.2 \\
Spouse & 154 & 11.6 \\
Son/daughter-in-law & 878 & 66.3 \\
Daughter/son-in-law & 81 & 6.1 \\
Grand children & 30 & 2.3 \\
Other family member & 17 & 1.3 \\
Unmarried son/daughter & 53 & 4.0 \\
Brother/sister-in-law & 18 & 1.4 \\
Other & 12 & 0.9 \\
Total & 1326 & 100.0 \\
\hline
\end{tabular}


Table 2. Major living arrangement of older persons, community, Nepal.

\begin{tabular}{ccc}
\hline Living Arrangement & Number & Percentage \\
\hline Alone & 82 & 6.2 \\
Spouse & 154 & 11.6 \\
Family & 1077 & 81.3 \\
Other & 12 & 0.9 \\
Total & 1326 & 100 \\
\hline
\end{tabular}

Table 3. Social variables and living arrangement of older people.

\begin{tabular}{|c|c|c|c|c|c|c|}
\hline & \multirow{2}{*}{ Variables } & \multirow{2}{*}{ Number } & \multicolumn{3}{|c|}{ Living arrangement (\%) } & \multirow{2}{*}{$\begin{array}{c}\text { Chi square } \\
\text { test }\end{array}$} \\
\hline & & & Alone & Spouse & Family & \\
\hline \multirow{2}{*}{ Sex } & Male & 522 & 4.8 & 14.9 & 80.3 & \multirow{2}{*}{0.000} \\
\hline & Female & 555 & 7.7 & 8.6 & 83.7 & \\
\hline \multirow{3}{*}{$\begin{array}{c}\text { Marital } \\
\text { Status }\end{array}$} & Married & 672 & 0.4 & 22.5 & 77.1 & \multirow{3}{*}{0.000} \\
\hline & Widow/widower & 596 & 10.9 & 0.2 & 88.9 & \\
\hline & Others & 45 & 31.1 & 4.4 & 64.4 & \\
\hline \multirow{6}{*}{ Ethnicity } & Brahmin & 136 & 11.0 & 9.6 & 79.4 & \multirow{6}{*}{0.087} \\
\hline & Chhetri & 258 & 5.8 & 15.9 & 78.3 & \\
\hline & Newar & 268 & 7.5 & 8.6 & 84.0 & \\
\hline & Tamang & 295 & 6.1 & 12.9 & 81.0 & \\
\hline & Dalit & 46 & 2.2 & 4.3 & 93.5 & \\
\hline & Other $^{* *}$ & 57 & 7.0 & 14.0 & 79.0 & \\
\hline \multirow{3}{*}{$\mathrm{SRH}^{*}$} & Good & 379 & 6.1 & 13.5 & 80.5 & \multirow{3}{*}{0.132} \\
\hline & Average & 677 & 6.5 & 12.6 & 80.9 & \\
\hline & Worse & 251 & 5.6 & 7.2 & 87.3 & \\
\hline \multirow{3}{*}{$\begin{array}{l}\text { Income } \\
\text { Situation }\end{array}$} & Less adequate & 389 & 11.1 & 11.6 & 77.4 & \multirow{3}{*}{0.000} \\
\hline & Just Adequate & 828 & 4.7 & 12.0 & 83.3 & \\
\hline & More than adequate & 94 & 0.0 & 9.6 & 90.4 & \\
\hline \multirow{3}{*}{ Age } & $60-69$ & 748 & 5.3 & 13.4 & 81.3 & \multirow{3}{*}{0.100} \\
\hline & $70-70$ & 397 & 7.6 & 10.6 & 81.9 & \\
\hline & $80+$ & 168 & 7.1 & 7.1 & 85.8 & \\
\hline \multirow{2}{*}{$\begin{array}{l}\text { Feeling of } \\
\text { insecurity }\end{array}$} & yes & 245 & 12.2 & 11.0 & 76.7 & \multirow{2}{*}{0.031} \\
\hline & no & 449 & 6.5 & 10.9 & 82.6 & \\
\hline
\end{tabular}

${ }^{\star}$ Self reported health ${ }^{* *}$ Includes Magar, Rai, Gurung and Terai origin castes.

The statistical test measured through the Chi-square test shows Sex of the respondents, marital status, ethnicity, income situation, and feeling of insecurity have significant differences in the living arrangement of older people in this study. Age and self-reported health have no effect on the living arrangement of older people. 


\section{Discussions}

In Asian nations, as in much of the rest of the world, there is an inverse relationship between economic well-being and the rate of aging [15]. Many less well-developed societies, despite the rapid growth of their older populations and perhaps due to their historical family-centered cultures, still lack a national policy focus on aging-related issues [16] [17] [18]. Most gerontological studies in Nepal have used small samples, and few focus on the older persons' issues. This study used a larger sample to describe the living arrangement of community-dwelling older adults in Nepal.

The living arrangement of the older people in Nepal is contingent on their level of social support. In particular, the availability of care from a spouse or child may be essential to the well-being of the very old or frail elderly. Older people depend on their children, particularly sons, for support and security in their old age [2] [9]. This study found $81.3 \%$ of older people are living with family members (son/daughter/grandchildren/other family members), 11.6 percent living with a spouse, and 6.2 percent living alone.

Different studies show similar types of living arrangements in Nepal. A community study from Kathmandu (2005) shows $83.7 \%$ living with children, $8.9 \%$ living alone, 5.7\% spouse, and $1.6 \%$ others [19]. This study further shows the proportion of living alone was quite high among older women (11.6\%) (Chalise \& Shrestha, 2006). Another study from Kathmandu shows 87.1 living with family members ( $72.5 \%$ three-generation and $14.7 \%$ two generations), $6.1 \%$ spouse, $2.9 \%$ alone, and $3.7 \%$ others [20]. A study of Rai ethnicity shows $73.3 \%$ living with children, $14.5 \%$ with the spouse, and $12.1 \%$ others [21]. A study from the countryside (2018) shows 88.9 .\% living with family members, $7.9 \%$ spouse, $2.7 \%$ alone and others $0.5 \%$ [22]. Its shows the traditional system of living arrangement is changing with time.

Demographic yearbook (DYB) of the United Nations 2017 conducted similar studies on global living arrangement of older persons and estimated in their database that majority of the older adult in the Asian nation is consistently dwelling with the presence of the child or Intragenerational co-residence. According to DHS 2011 [23] study carried out across the 143 countries or areas, the median proportion of persons aged 60 years or over living alone was 12 percent, with estimates ranging from a low of less than 1 percent in both Afghanistan and $\mathrm{Pa}$ kistan to 34 percent in Lithuania. For half of the countries, the proportion living alone was between 7 and 21 percent. Most countries in Europe were above the 75th percentile, however, in 23 of the 35 European countries with available data, more than one in four older persons lived alone. Countries below the 25th percentile were mostly in Asia and Africa. According to DHS 2011 data, older people living alone were $3.9 \%$, with spouse only $12.4 \%$, and with children were $75.4 \%$ in Nepal [23].

National and international literature has reported that older adults who live with their partners have better levels of physical and mental health [24] [25]. It is 
possible that the spouse, also experiencing the aging process, has more empathy with their partner and, together, creates bonds of mutual support in daily life, overcoming the limitations imposed by old age. Social interaction in the home environment between the older adults and their partners can also avoid social isolation, as well as provide effective and material support. The social support network of older people who live with their spouses can favor better quality of life scores in this group, due to the mediating role between these variables [26].

Although, there are fewer studies conducted to co-residence with children to older parents in Nepal, research done in Europe has evidenced that sharing these family burdens with a partner especially in younger adults as well as an older adult is beneficial for health due to a variety of material and psychosocial reasons. However, the association between living alone and health decreases with age that affects their residential independence, [27]. Children and closer relatives are the major Primary caretakers of older adults in Nepalese society as well as other counterparts in south Asian nations.

Ad hoc studies show older people of Nepal are facing poor housing and suffer from either physical, mental, or chronic diseases. Although the majority of the elderly have their own house, fewer studies have included the need for healthier lives for the elderly by increasing the supportive and comfortable housing as geriatric-friendly communities. The modification and retrofitting with the adoption of universal design in their existing residence will accommodate the physical needs of older adults associated with their chronic disease and disability. Nepalese Older adults wish to reside in familiar surroundings, taking pride in living in their same old house rather than unfamiliar ones. However, those who do not have children are prone to poor living conditions and wellbeing which can even possibly lead to increased socio-biomedical vulnerabilities such as homelessness. Due to the limitation of the available evidenced studies, self-rated and abuse perception of older adults as well as homelessness, older adults are less included. The problem of the developing countries is not having a good database and being unable to perform analysis but there is less indication of the available legal mechanism that assesses the elder abuse within the potential legislative framework of community living arrangement to older persons.

This study found a significantly high number of males living with spouses compared to women. It may be due to the cultural norms that males should be fewer years older or girls prefer to get married to a person who is mature. Notably, women present more interest in caregiving and with a sense of obligation to family matters [27]. The proportion of older people living with family members is highest in Dalit ethnicity. It may be due to Dalits children being less mobile (migrant) compared to other ethnicity included in this study. This study found a significantly higher number of single people living alone compared to married and widows/widowers. The exact reason for this is not clear.

This study shows older people whose income is quite low are living alone compared to those who have more than adequate income. This is just contrary to other studies, there was a predominance of a higher income among elderly 
living alone [26] [28]. The exact reason behind this is not known, but people who are living alone are majority from single, unmarried, divorced, and majority women as well. In the Nepali culture, males dominate women in economic activity so it may be another reason.

\section{Conclusion}

More than 80 percent of older people were living with their family members. Older people in Nepal prefer to live with their children. However, the traditional support system is changing in the 21 st centenary due to globalization and the increase in the mobility of younger generations. The government of Nepal should adopt the social security and traditional living arrangement of older people in a promotive manner by making it more reliable as many people are going to live either in the spouse or alone in upcoming days. The local and national governments in Nepal should come up with integrated legal frameworks to strengthen the social security of the elderly such as awareness programs and rights protection initiatives for improved care and decreased vulnerability.

\section{Author Contributions}

HNC conceived and analyzed the data. SNC and AU drafted the first draft. HNC supported to finalize the paper. Finally, all three authors discussed together to finalize the paper.

\section{Conflicts of Interest}

The authors declare no conflicts of interest regarding the publication of this paper.

\section{References}

[1] Chalise, H.N. (2019) Aging: Basic Concept. American Journal of Biomedical Science and Research, 1, 8-10. https://doi.org/10.34297/AJBSR.2019.01.000503

[2] Chalise, H.N. and Brightman, J. (2006) Aging Trend: Population Aging in Nepal. Geriatrics \& Gerontology International, 6, 199-204. https://doi.org/10.1111/j.1447-0594.2006.00347.x

[3] Chalise, H.N., Kai, I. and Saito, T. (2017) Self-Reported Health: A Study of Older Adults from a Developing Country-Nepal. BioScience Trends, 1, 102-107.

[4] Chalise, H.N., Saito, T. and Kai, I. (2008) Functional Disability in Activities of Daily Living and Instrumental Activities of Daily Living among Nepalese Newar Elderly. Public Health, 122, 394-396. https://doi.org/10.1016/j.puhe.2007.07.015

[5] Chalise, H.N. (2010) Social Support and Its Correlation to Loneliness and Subjective Well-Being of Nepalese Older Adults. Asian Social Work and Policy Review, 4, 1-25. https://doi.org/10.1111/j.1753-1411.2009.00034.x

[6] Khanal, B. and Chalise, H.N. (2020) Caregiver Burden among Informal Caregivers of Rural Elderly in Nepal. Journal of Health Care and Research, 1, 149-156. https://doi.org/10.36502/2020/hcr.6173

[7] Bongaarts, J. and Zimmer, Z. (2002) Living Arrangements of Older Adults in the 
Developing World: An Analysis of Demographic and Health Survey Household Surveys. Journal of Gerontology: Series B, 57, S145-S157. https://doi.org/10.1093/geronb/57.3.S145

[8] Chalise, H.N. and Ghimire-Risal, P.K. (2018) Does Population Ageing Affect the Least Developed Country Like Nepal? Open Access Journal of Gerontology \& Geriatric Medicine, 3, Article ID: 555618.

[9] Chalise, H.N. (2006) Demographic Situation of Population Ageing in Nepal. Kathmandu University Medical Journal, 4, 354-362.

[10] Malakar, I. and Chalise, H.N. (2019) Perception of Elderly towards Social Security allowances in Nepal. South Asian Journal of Social Studies and Economics, 2, 1-9. https://doi.org/10.9734/sajsse/2018/v2i430008

[11] Chalise, H.N., Saito, T., Takahashi, M. and Kai, I. (2007) Relationship Specialization amongst Sources and Receivers of Social Support and Its Correlations with Loneliness and Subjective Well-Being: A Cross-Sectional Study of Nepalese older adults. Archives of Gerontology and Geriatrics, 44, 299-314. https://doi.org/10.1016/j.archger.2006.07.001

[12] Panigrahi, A.K. (2009) Determinants of Living Arrangements of Elderly in Orissa: An Analysis. Working Papers 228, Institute for Social and Economic Change, Bangalore.

[13] Bisht, P.S., Pathak, R.S., Subedi, G., Shakya, D.V. and Gautam, K.M. (2012) Health and Social Care Needs Assessment of Elderly: The Context of Piloting Service Developments and Care of Elderly in Pharping, Kathmandu, Nepal. Tribhuvan University, Ageing Nepal, Kathmandu, Nepal and United Nations Population Fund.

[14] Chalise, H.N. and Rosenberg, E. (2019) Social and Health Status of Community-Dwelling Older Adults in Nepal. Advances in Aging Research, 8, 63-74. https://doi.org/10.4236/aar.2019.84005

[15] Holmes, W.R. and Joseph, J. (2011) Social Participation and Healthy Ageing: A Neglected, Significant Protective Factor for Chronic Non-Communicable Conditions. Globalization and Health, 7, Article No. 43. https://doi.org/10.1186/1744-8603-7-43

[16] Joshi, M.R. and Chalise, H.N. (2021). Elderly abuse and quality of life: A study of community living older people of Nepal. Journal of Medical Evidence, 2, 113-119. https://doi.org/10.4103/JME.JME 14020

[17] Chalise, H.N. and Khanal, B. (2020) Functional Disability on Instrumental/Activities of Daily Livings among Rural Older People in Nepal: Functional Limitations among Rural Older People of Nepal. Journal of Karnali Academy of Health Sciences, 3, 1-6.

[18] Chalise, H.N. and Paudel, B.R. (2020) Elderly Abuse among Community-Living Older Adults of Least Developed Country-Nepal. Archives of Physical Medicine and Rehabilitation, 1, 1-8.

[19] Chalise, H.N. and Shrestha, S. (2005) Situation of the Elderly in the Himalayan Kingdom of Nepal. Indian Journal of Social Work, 66, 136-143.

[20] Chalise, H.N. (2012) Socio-Demographic and Health Status of Nepalese Elderly. Indian Journal of Gerontology, 26, 151-160.

[21] Chalise, H.N. and Rai, S.L. (2013) Prevalence and Correlates of Depression among Nepalese Rai Older Adults. Journal of Gerontology and Geriatric Research, 2, 1-5.

[22] Joshi, M.R., Chalise, H.N. and Khatiwada, P.P. (2018) Quality of Life of Nepalese Elderly Living in Rural Nepal. Journal of Gerontology and Geriatric Research, 7, Article No. 484.

[23] Department of Economic and Social Affairs, Population Division, United Nations 
(2017) Living Arrangements of Older Persons: A Report on an Expanded International Dataset. United Nations, New York.

https://www.un.org/en/development/desa/population/publications/pdf/ageing/Livi ngArrangements.pdf

[24] Kim, H.J. and Fredriksen-Goldsen, K.I. (2016) Living Arrangement and Loneliness among Lesbian, Gay, and Bisexual Older Adults. Gerontologist, 56, 548-558.

https://doi.org/10.1093/geront/gnu083

[25] Henning-Smith, C. (2016) Quality of Life and Psychological Distress among Older Adults: The Role of Living Arrangements. Journal of Applied Gerontology, 35, 39-61. https://doi.org/10.1177/0733464814530805

[26] Bolina, A.F., Araújo, M.C., Hass, V.J. and Tavares, D.M.S. (2021) Association between Living Arrangement and Quality of Life for Older Adults in the Community. Revista Latino-Americana de Enfermagem, 29, Article No. e3401.

https://doi.org/10.1590/1518-8345.4051.3401

[27] Bolina, A.F. and Tavares, D.M.S. (2016) Living Arrangements of the Elderly and the Sociodemographic and Health Determinants: A Longitudinal Study. Revista Latino-Americana de Enfermagem, 24, Article No. e2737. https://doi.org/10.1590/1518-8345.0668.2737

[28] Hu, Y., Leinonen, T., van Hedel, K., Myrskylä, M. and Martikainen, P. (2019) The Relationship between Living Arrangements and Higher Use of Hospital Care at Middle and Older Ages: To What Extent Do Observed and Unobserved Individual Characteristics Explain This Association? BMC Public Health, 19, Article No. 1011. https://doi.org/10.1186/s12889-019-7296-x 